Bull. Mater. Sci., Vol. 21, No. 1, February 1998, pp. 93-97. (C) Printed in India.

\title{
Effect of fillers on acousto ultrasonic response in GRP composites
}

\author{
PRAVESH KUMAR \\ MTC Division, National Metallurgical Laboratory, Jamshedpur 831007 , India
}

MS received 20 January 1996; revised 24 December 1996

\begin{abstract}
In recent years, there has been a wide interest in fillers which improve the quality and performance of fibre composites when mixed in a small quantity in the matrix. In the present work the effect of addition of mica and graphite powders in cross ply glass fibre reinforced plastic (GRP) composites has been studied by using acousto ultrasonic (AU) technique. The mechanical strengths of these composites were correlated with fibre volume fraction $\left(V_{f}\right)$. The stress wave factor (SWF) was evaluated and correlated with tensile/flexural strengths of these composite specimens. The observations show a linear relationship between the SWF values and strength of unfilled and filled GRP composites.
\end{abstract}

Keywords. Stress wave factor; filled and unfilled GRP; acousto ultrasonic; fibre volume fraction.

\section{Introduction}

Glass fibre reinforced plastic (GRP) composites have wide acceptance by many industries because of their high strength to weight ratio, good corrosion resistance and availability of design criteria. It has been seen that fillers are used in many applications. The filled composites exhibit moderately improved mechanical properties, damping, attenuation as well as thermal stability characteristic depending on the kind of filler employed.

Many cases have been discussed and illustrated where the highest concentration of filler and therefore maximum cost reduction is highly advantageous. Conversely, the limitations of filler use are also described. The filler selection is primarily determined by the particle size distribution. Average particle size is useful for evaluating specific properties of fillers. Quality control of these fillers is usually exercised by controlling the coarseness and average particle size control of coarseness is essential. However, instead of particle size, particle packing is most significant.

Ferrigno (1978) described and illustrated the advantageous use of fillers in fibre-reinforced composite material. Srivastava et al (1988) used fly ash as a filler in glass fibre-reinforced plastic composites and determined the fracture toughness and fracture surface energy. Ramsteiner and Theysohn (1984) studied the tensile behaviour of filled composites. Lorne (1992) studied filled glass fibre-reinforced polyester composites in aqueous environments and reported that GRP are used extensively in fabrication of underground piping and storage vessels for water and sewage applications for reasons of economy. To compromise between the cost and mechanical performance, mica and graphite powder have been used in this study. Nondestructive testing of GRP composites is of great significance if the GRP composites are to be used with greater reliability. Therefore, the mechanical and nondestructive AU testing of fabricated GRP composites with and without fillers was extensively studied in the present paper.

\section{Experimental}

\subsection{Preparation of samples}

Cross ply composite laminates were fabricated in laboratory by hand lay-up technique. This is a conventional technique being used from the ages for its ease and low cost. In this technique $E$ glass fibre $\left(0 / 90^{\circ}\right)$ was used as a reinforcing medium; resin (Cy205) and hardener (Hy951) were used as matrix. The resin and hardener were mixed in the ratio of $10: 1$ for about five min at room temperature. Thereafter, the mixture was kept at $60^{\circ} \mathrm{C}$ for about $30 \mathrm{~min}$ to avoid air bubbles, voids and to get proper mixing. The mixture of resin and hardener was poured in a mould which was coated with the releasing agent. In this mould a layer of woven glass fibre mat was laid. After evenly spreading the resin in mould another layer of woven glass fibre mat was laid and this process was repeated until the required thickness was obtained. Thereafter, a suitable dead weight was placed on the top plate of the mould for removal of excess resin and air bubbles. After curing, GRP plates were removed from the mould. Curing time at room temperature was observed to be about $24 \mathrm{~h}$.

The filler chosen in the present study is graphite. It is a crystalline carbon formed by mineralogical process and is uniform and provides good acid and alkali resistance. GRP plates with muscovite mica and graphite powders as fillers were fabricated in laboratory in the same manner as described above. 
The particle sizes were measured by sieving; mica powder, particle size $100 \mu$ and $5 \%$ by weight, was used and was mixed in matrix (resin : hardener :: $10: 1$ ). Similarly, graphite powder, particle size $100 \mu$ and $5 \%$ by weight, was mixed in matrix. The mechanical properties of these fillers are given in table 1 . The composite plates were fabricated with least possible variation in fibre volume fraction $\left(V_{\mathrm{f}}\right)$ achieving a constant $V_{\mathrm{f}}$ of $50 \%$. Also, composite sheets were fabricated with varying $V_{f}$. Variation in $V_{f}$ was achieved by controlling the amount of fibre being used while making the composites. Fibre volume fraction of the sample was measured by acid digestation high temperature heating process as per BIS specification HIVID 4 (001S) P1.

The mica-powder-filled GRP composite plates and graphite-powder-filled GRP composite plates were used for comparative study of their mechanical properties vis-à-vis GRP composites.

\subsection{Evaluation of tensile and flexural strengths}

Thirty tensile specimens were made from the fabricated composite sheets in dog bone shape for tensile strength.
The SWF values at different locations were obtained and tensile strength was evaluated using Hounsfield tensometer.

Flexural strength of unfilled and filled composites, was obtained under three-point bending test using an universal testing machine. In three-point bending, when a force is applied at the centre of the upper surface of an end supported beam as in ASTM D-790, the upper surface is under compression and the lower surface is in tension. Maximum stress is applied only to the surface in tension. The decreasing strain through the cross section (from lower to upper surface) had the effect of providing somewhat higher flexural than tensile yield strength. This is especially pronounced for matrices having elongation greater than about $5 \%$. Inherently tough polymers may obtain higher flexural strength with high aspect ratio fillers or solid fillers treated with coupling agents. The flexural strength $\left(\sigma_{\mathrm{m}}\right)$ is evaluated using the following expression:

$$
\sigma_{\mathrm{m}}=3 P L / 2 b h^{2},
$$

where, $P$ is the maximum load in $\mathrm{Kgf}, b$ the specimen width, $h$ the thickness of the specimen and $L$ the distance between two spans.

Table 1. Properties of mica and graphite particles used in study.

\begin{tabular}{lccccl}
\hline Materials & Size & $\begin{array}{c}\text { Tensile } \\
\text { modulus } \\
\left(\mathrm{GN} / \mathrm{m}^{2}\right)\end{array}$ & $\begin{array}{c}\text { Density } \\
(\mathrm{g} / \mathrm{cc})\end{array}$ & $\begin{array}{c}\text { Compressive } \\
\text { strength } \\
\left(\mathrm{MN} / \mathrm{m}^{2}\right)\end{array}$ & Response \\
\hline Mica powder & $100 \mu$ & 172 & $2 \cdot 13$ & 72.15 & Very soft/mild \\
Graphite powder & $100 \mu$ & 1250 & 3.20 & 80.60 & Tough/brittle \\
\hline
\end{tabular}

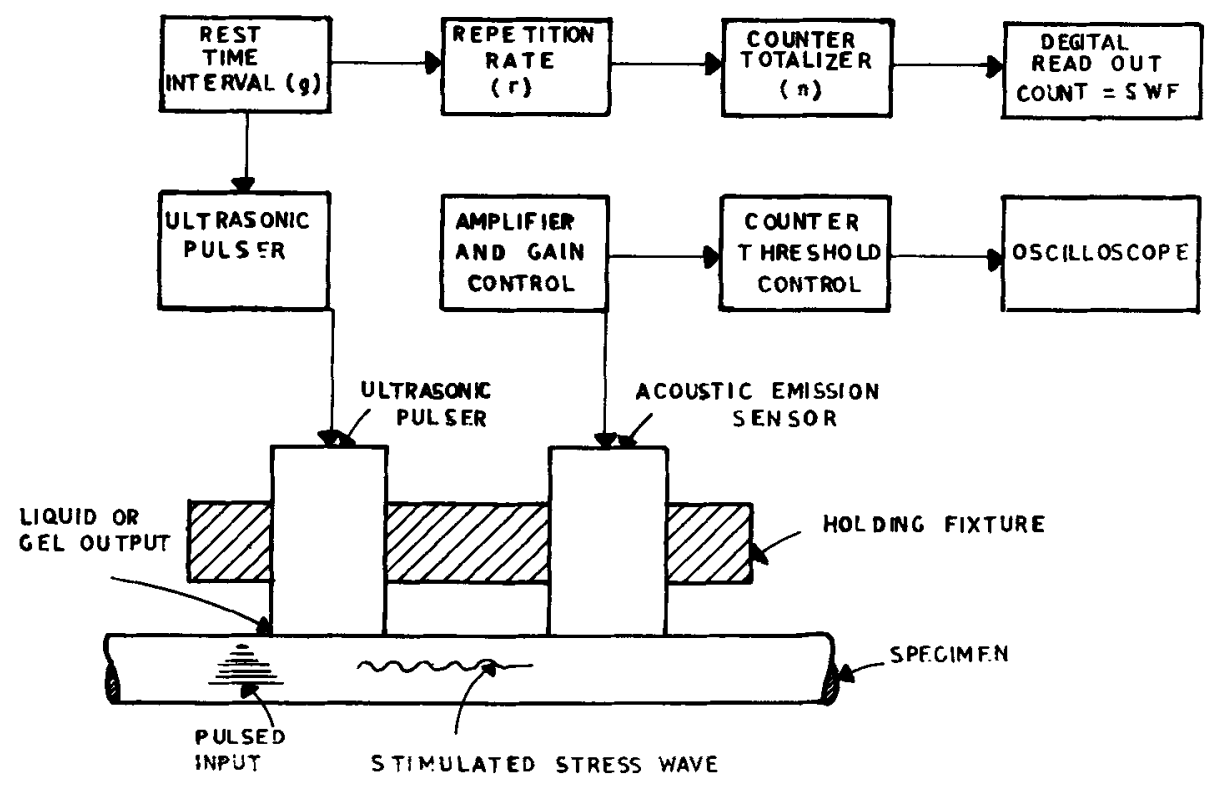

Figure 1. Block diagram for measurement of stress wave factor. 


\subsection{Acousto ultrasonic testing}

The fabricated composites were characterized by $\mathrm{AU}$ technique according to ASTM standard E 1495. This is relatively a new non-destructive testing technique and is essentially an amalgamation of the two techniques: acoustic emission and ultrasonic technique, in which ultrasonic pulses are induced in the material by a pulser. The induced pulses interact with voids and cracks present inside the material and the pulse thus gets modulated. The modulated signals are picked up by another piezoelectric acoustic emission sensor called receiver. These

\section{TENSILE STRENGTH (MPa)}

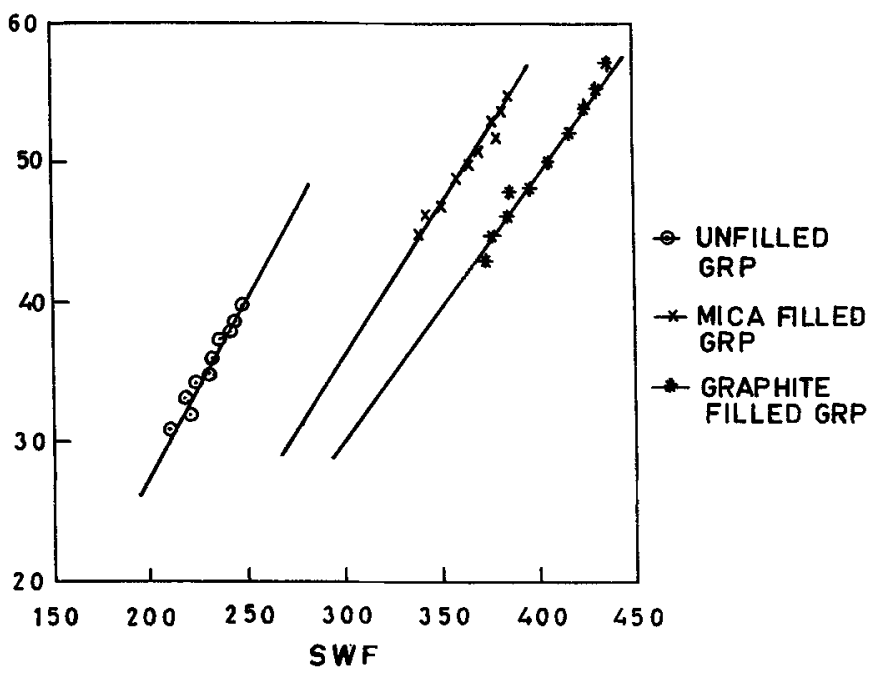

Figure 2. Variation of tensile strength with SWF of GRP composites.

\section{FLEXURAL STRENGTH (MPa)}

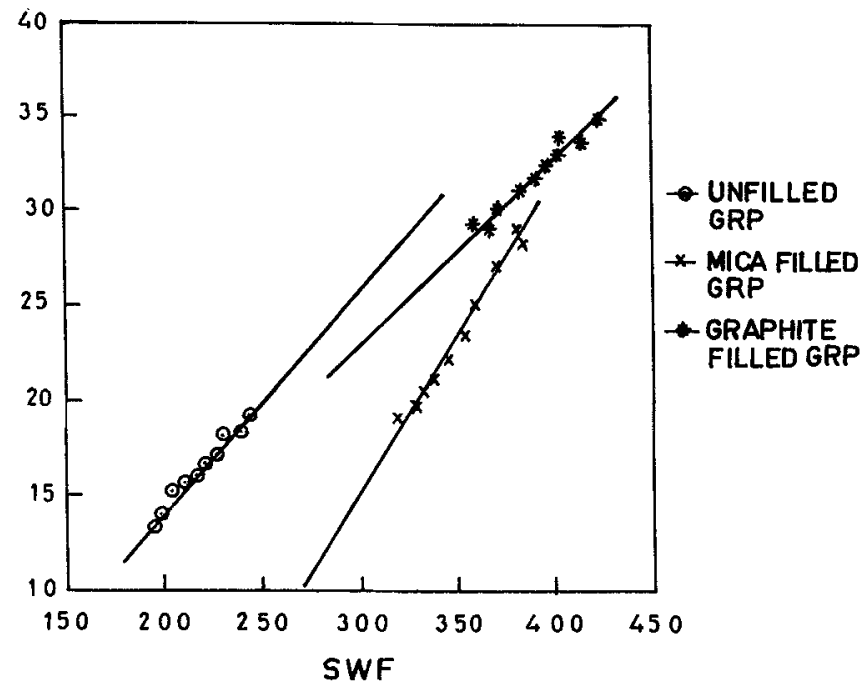

Figure 3. Variation of llexural strength with SWF of GRP composites. pulses pass through a preamplifier and to an amplifier and finally to the analysing circuit. For characterization of material quality, one has to calculate stress wave factor (SWF). It was defined by Vary (1980) as:

$$
\mathrm{SWF}=g r n,
$$

where, $g$ is the pulse rate (ultrasonic pulse), $r$ the repetition rate (time) and $n$ the number of pulses which cross a fixed threshold voltage.

In other words, multiplication of these parameters would give stress wave factor of a particular material. Therefore SWF was evaluated in the present investigation by using AET-206 AU instrument. The SWF values thus obtained at different locations on unfilled and filled GRP-composites when the noise interference was minimum. Transducers were firmly placed at a distance of $4 \mathrm{~cm}$ against the specimen to avoid changes in the pressure during the time when pulser was activated. The block diagram of the apparatus for measurement of SWF is shown in figure 1.

\section{Results and discussion}

Figures 2 and 3 show the relationship between the SWF and tensile strength, and SWF and flexural strength of unfilled GRP, mica- and graphite-filled GRP composites. As far as unfilled and mica-filled composites are concerned, the SWF values were found to be lower whereas graphite filled composites showed significantly higher values. The correlation coefficient $r$ and student $t$ values were evaluated from the plots of SWF and tensile/flexural strengths and are listed in table 2 . The results show that a good correlation exists between SWF values and the mechanical strengths in the unfilled as well as filled composites.

Figures 4-6 show and describe tensile and flexural strength with respect to fibre volume fraction. Fillers affect tensile properties according to their packing characteristics, size and interfacial bonding. The spaces between particles are assumed to be filled with matrix and no voids or air bubbles are present. Under these conditions, for a given system, the matrix volume is at a minimum and acts as individual segment or pocket to support tensile load.

Table 2. Correlation coefficient $(r)$ values of GRP composites.

\begin{tabular}{lcc}
\hline Materials & $\begin{array}{c}\text { Tensile strength } \\
\text { correlation } \\
\text { coefficient } \\
(r)\end{array}$ & $\begin{array}{c}\text { Flexural strength } \\
\text { correlation } \\
\text { coefficient } \\
(r)\end{array}$ \\
\hline Unfilled GRP & 0.945 & 0.895 \\
Mica filled GRP & 0.964 & 0.927 \\
Graphite filled GRP & 0.986 & 0.976 \\
\hline
\end{tabular}


Flexural testing can be used for grading specimens in materials evaluation, process development and improvement and quality control. However, a true correlation

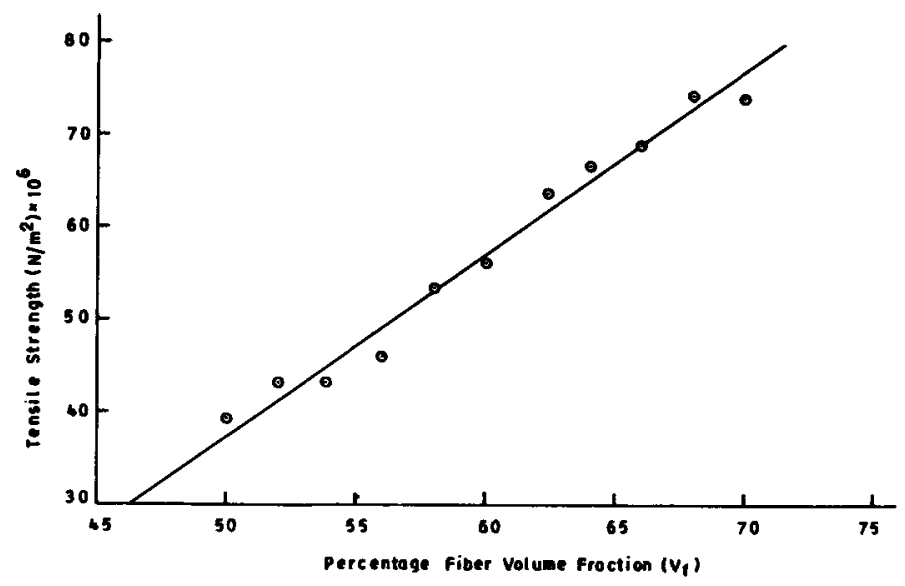

Figure 4. Variation of tensile strength with percentage $V_{\mathrm{f}}$ of unfilled GRP composite. between flexural properties and other mechanical properties has never been established. There are many subtle variables affecting bending test strength so that the problem of correlating flexural data with the more basic properties can outweigh all advantages of meaningful design data.

In the present investigation, it was observed that the quality of virgin GRP composite is improved by adding graphite powder, but this is not so when mica powder was added which has been frequently used in composite development programmes. The reason being that the carbon atoms of the graphite powder easily reacted with the epoxide of epoxy resin which in turn contributed for the improved cohesive strength. In the mica powder $\mathrm{K}_{2} \mathrm{Al}_{4}\left(\mathrm{Al}_{2} \mathrm{Si}_{6} \mathrm{O}_{20}\right)(\mathrm{OH})_{4}$ having chemical composition as: $\mathrm{SiO}_{2}-47.9 \%, \mathrm{Al}_{2} \mathrm{O}_{3}-33.13 \%, \mathrm{MgO}-0.69 \%, \mathrm{Fe}_{2} \mathrm{O}_{3}-2.04 \%$, $\mathrm{K}_{2} \mathrm{O}-9.8 \%, \mathrm{Na}_{2} \mathrm{O}-0.8 \%, \mathrm{CaO}-0.5 \%, \mathrm{TiO}_{2}-0.65 \%, \mathrm{Cr}_{2} \mathrm{O}_{3}-$ $0.65 \%$. These do not easily dissolve in the epoxy resin and, therefore, will not help to increase strength of the composite. The higher SWF values obtained would generally provide a means of rating the efficiency of dynamic
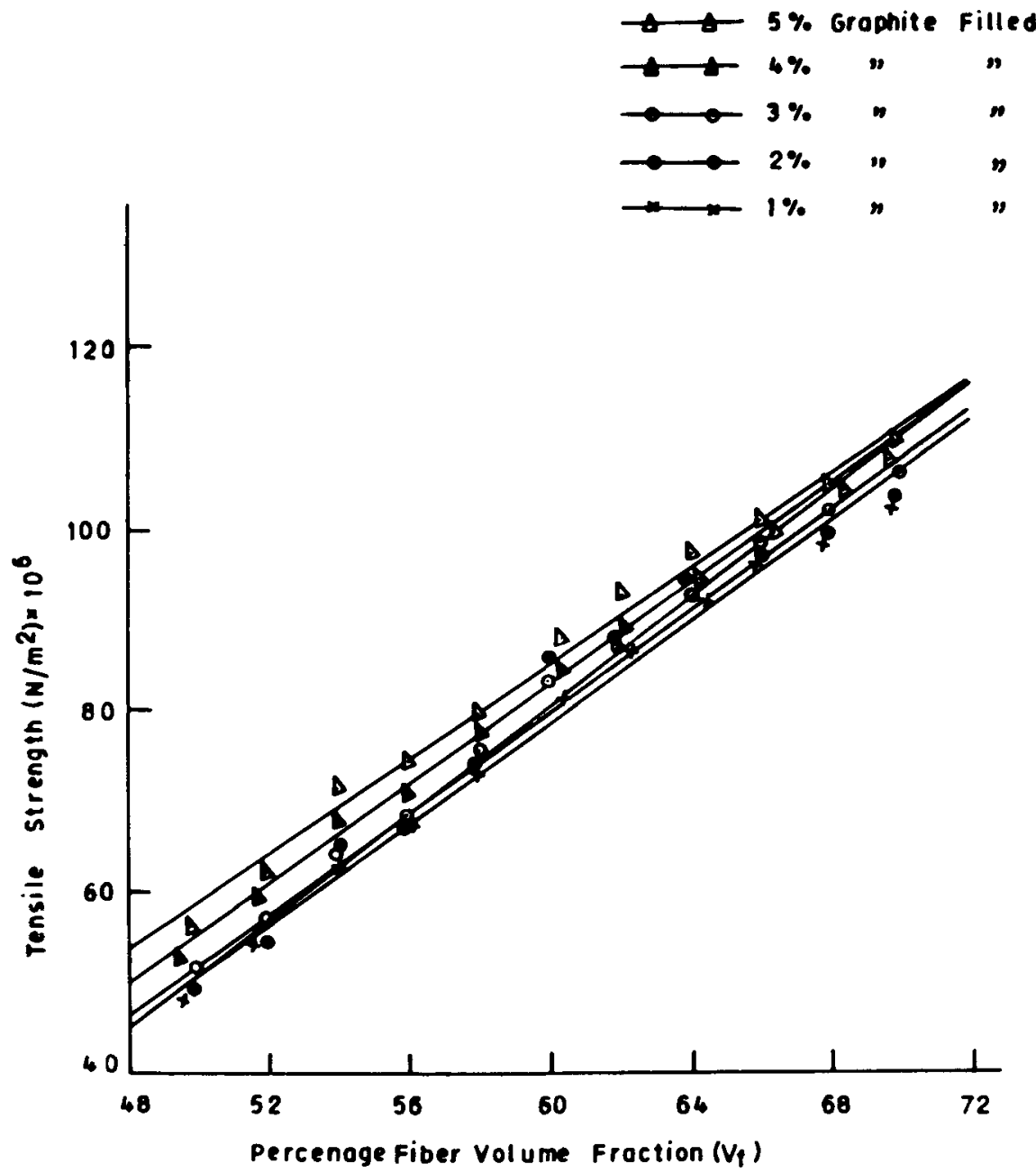

Figure 5. Variation of tensile strength with percentage $V_{\mathrm{f}}$ of graphite filled GRP composite. 

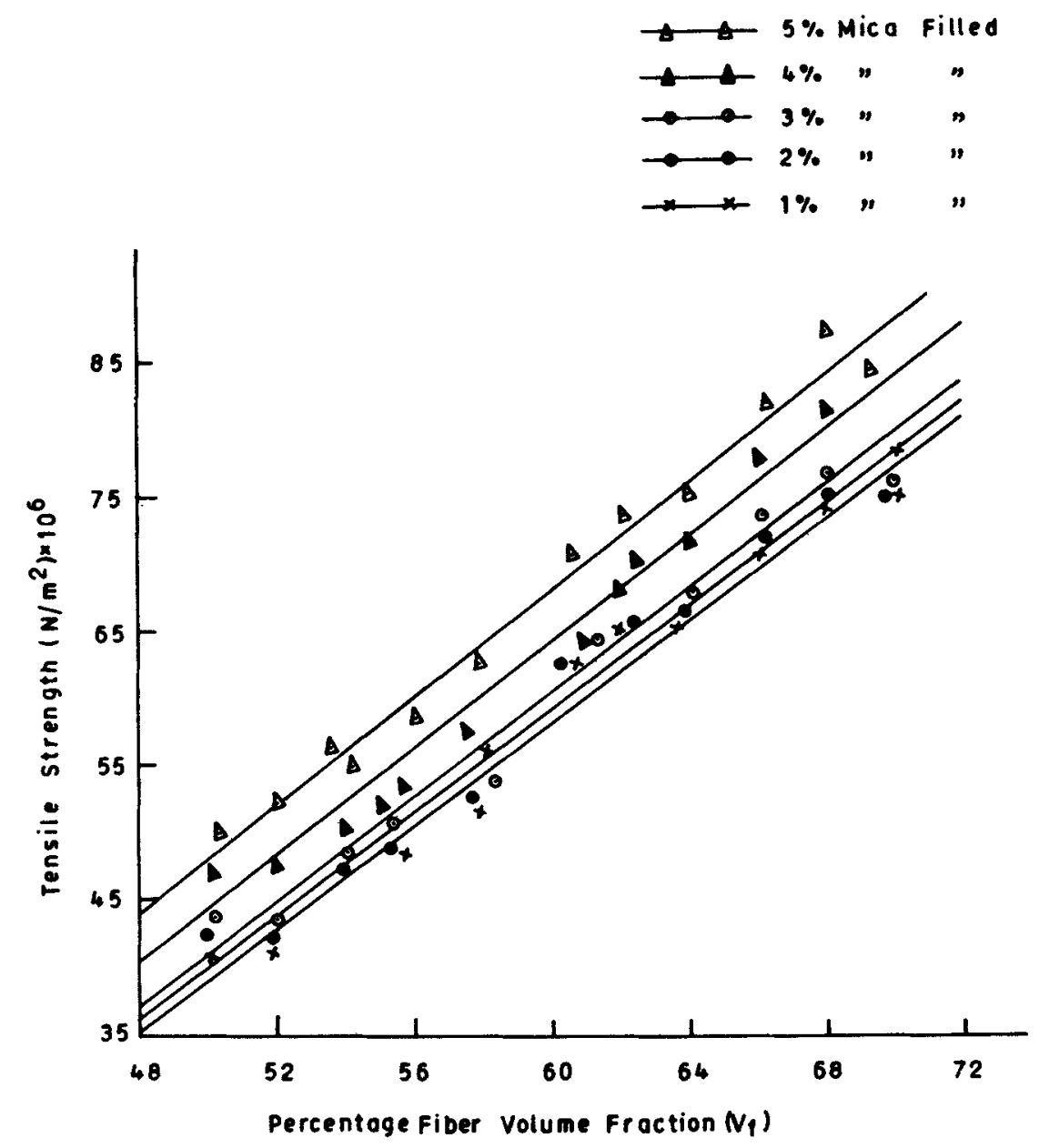

Figure 6. Variation of tensle strength with percentage $V_{f}$ of mica tilled GRP composite.

strain energy transfer in a GRP composite specimen. This in turn would provide information about the quality of the material. The ultimate purpose of $\mathrm{AU}$ approach is to relate efficiency of stress wave energy propagation in a material.

For fibre-reinforced composite, better stress wave energy transfer means better transmission of dynamic strain, better load distribution, greater strength and greater fracture resistance. However, the lower values of the SWF would suggest that the material has a region of higher attenuation which may be due to local variation in microstructural features, porosity, bond quality, cure state and microcrack population of the composites.

It was found in the present investigation that the SWF is very much reproducible when background noise at high gain was deleted. This was achieved by fixing up a threshold voltage. The factors that affect the experimental results could be coupling, contact pressure, pulse rate, gain, frequency and threshold. If all these are kept constant, then the SWF should reflect the variation in the composition of the specimen under test.

\section{Conclusions}

Based on the present study the following conclusions can be drawn:

(I) The mechanical strengths i.e. tensile and flexural, were found to vary with SWF as well as with fibre volume fraction in the GRP composite with and without fillers.

(II) Fillers were found to be extremely useful in improving the strength SWF of the GRP composites.

(III) Out of the two fillers used in the present investigation graphite was found to improve the strength of unfilled GRP composites significantly.

\section{References}

Ferrigno T H 1978 Principle of filler selection and use, in Handbook of fillers and reinforcement for plastic (eds) H S Katz and J V Mikwski (New York: Van Nostrand Reinhold Co.) p. 11

Lorne W D 1992 Diss. Abstr. Int. 528

Ramesteiner F and Theysohn R 1984 Composites 15121

Srivastava V K, Shembekar P S and Prakash R 1988 Comp. Struct. 10271

Vary A 1980 J. Mater. Eval. 40650 